\title{
Ionospheric Electron Density Concurrently Derived by TIP and GOX of FORMOSAT-3/COSMIC
}

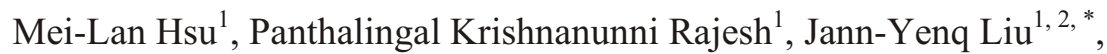 \\ Lung-Chih Tsai ${ }^{1,2}$, Ho-Fang Tsai ${ }^{3}$, Chien-Hung Lin ${ }^{4}$, Kenneth F. Dymond ${ }^{5}$, Clayton Coker ${ }^{5}$, \\ Damien H. Chua ${ }^{5}$, Scott A. Budzien ${ }^{5}$, and Chio-Zong Cheng ${ }^{4}$ \\ ${ }^{1}$ Institute of Space Science, National Central University, Chung-Li, Taiwan, ROC \\ ${ }^{2}$ Center for Space and Remote Sensing Research, National Central University, Chung-Li, Taiwan, ROC \\ ${ }^{3}$ Center Weather Bureau, Taipei, Taiwan, ROC \\ ${ }^{4}$ Plasma and Space Science Center, National Cheng Kung University, Tainan, Taiwan, ROC \\ ${ }^{5}$ E. O. Hulburt Center for Space Research, Naval Research Laboratory, Washington, District of Columbia, USA
}

Received 24 July 2007, accepted 24 April 2008

\begin{abstract}
The tiny ionospheric photometer (TIP) and GPS occultation experiment (GOX) onboard FORMOSAT-3/COSMIC (F3/C) are employed to measure the OI $135.6 \mathrm{~nm}$ intensities in the nadir direction and the total electron content (TEC) between the F3/C and GPS satellite in the ionosphere, respectively. Due to its very high sensitivity $\sim 600$ counts/Rayleigh and rather narrow nadir pointing $3.8^{\circ}$ circular field-of-view, the TIP provides accurate characterization of ionospheric electron density gradients in the horizontal direction. Meanwhile, a technique of the low earth orbit (LEO) tomography is applied to analyze the GOX data obtaining the 3D distribution of ionosphere electron density. Here, we combine the two observations to carry out the LEO-TIP tomographic inversions, and demonstrate that the peak electron density $\left(\mathrm{NmF}_{2}\right)$ retrieved from the TIP combined together with the peak altitude $\left(\mathrm{hmF}_{2}\right)$ information from the LEO tomography profiles provides more realistic electron density.
\end{abstract}

Key words: Tiny ionospheric photometer (TIP), GPS occultation experiment (GOX), FORMOSAT-3/COSMIC (F3/C), LEO tomography, LEO-TIP tomographic inversion, Ionospheric electron density

Citation: Hsu, M. L., P. K. Rajesh, J. Y. Liu, L. C. Tsai, H. F. Tsai, C. H. Lin, K. F. Dymond, C. Coker, D. H. Chua, S. A. Budzien, and C. Z. Cheng, 2009: Ionospheric electron density concurrently derived by TIP and GOX of FORMOSAT-3/COSMIC. Terr. Atmos. Ocean. Sci., 20, 207-214, doi: 10.3319/ TAO.2008.04.24.02(F3C)

\section{INTRODUCTION}

To improve the global weather prediction and space weather monitoring, six microsatellites termed the Formosa Satellite 3 - Constellation Observing System for Meteorology, Ionosphere, and Climate (FORMOSAT-3/COSMIC; F3/C) were launched into circular low-earth orbits (LEOs) from Vandenberg Air Force Base, California, at 0140 UTC 15 April 2006. Each microsatellite of the joint Taiwan-US satellite constellation mission has a GPS occultation experiment (GOX) payload to operate the atmospheric and ionospheric radio occultation, a tiny ionospheric photometer (TIP) to observe the nighttime ionospheric airglow OI $135.6 \mathrm{~nm}$ emission (Fig. 1), and a tri-band beacon (TBB) to tomographically estimate fine structures of ionospheric elec-

\footnotetext{
* Corresponding author

E-mail:jyliu@jupiter.ss.ncu.edu.tw
}

tron density on the satellite-to-receiver plane (Rocken et al. 2000; Cheng 2006). While the GOX daily observes about 2500 vertical electron density distributions up to the satellite altitude (Schreiner et al. 2006; Lei et al. 2007; Lin et al. 2007; Lin et al. 2009; Tsai et al. 2009), the TIP provides accurate horizontal gradients of nighttime electron density (Chua et al. 2009; Coker et al. 2009; Dymond et al. 2009).

The radio occultation technique was first used by the Mariner IV Mars exploration mission in 1965 observing Mars' atmosphere structures (Fjeldbo and Eshleman 1968) and later on by Mariner V Venus mission, other planetary and lunar probes, etc. (Fjeldbo et al. 1971; Yunck 2002). The technique was not applied to Earth's atmosphere observation until an experimental satellite called GPS/MET in 1995. By using a LEO satellite, named as MicroLab 1, at about $735 \mathrm{~km}$ altitude and $70^{\circ}$ inclination angle to receive the ultra 


\section{TIP+GOX tomography GOX calibrated TEC}

\section{TIP radiance $\rightarrow$ IEC}

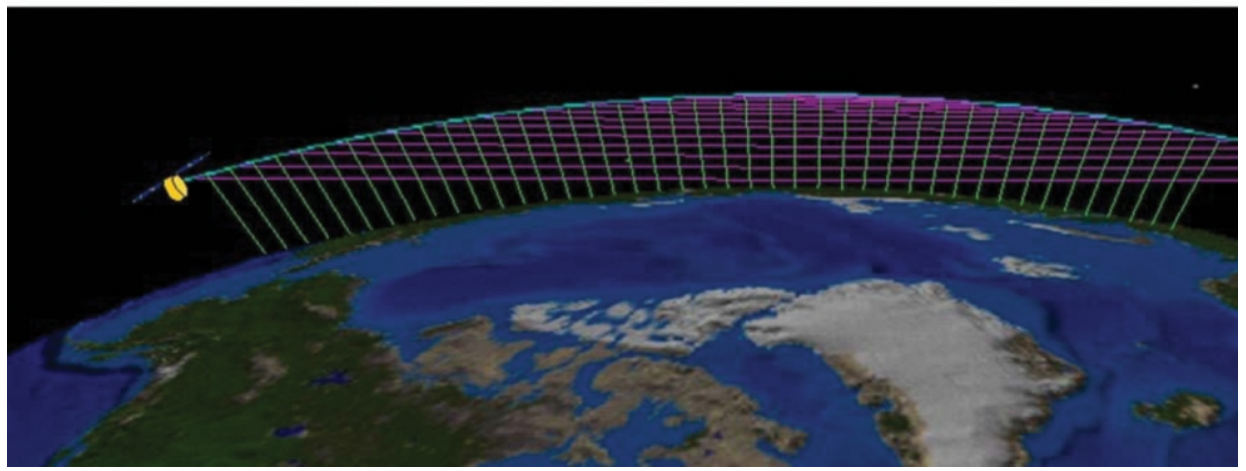

Fig. 1. Ionospheric TIP-LEO (TIP+GOX) tomography. The green and pink lines denote the GOX limb scan (calibrated TEC) and the TIP intensity (converted IEC), respectively.

high frequency (UHF; 1.5 and $1.2 \mathrm{GHz}$ ) radio signal transmitted by GPS satellites at an altitude of $20200 \mathrm{~km}$, GPS/ MET is able to sound the ionosphere from the orbit altitude to Earth's surface and retrieve vertical profiles of ionospheric electron density using the Abel integral transform under the assumption of spherical symmetry at the locality of occultation. Several studies examine the accuracy of retrieved GPS/MET electron density profiles and show the Abel inversion being suffered from the spherical symmetry assumption (Hajj and Romans 1998; Schreiner et al. 1999; Tsai et al. 2001; Tsai and Tsai 2004). Tsai et al. (2001) find that an asymmetry at the equatorial anomaly most likely causes the Abel inversion to systematically under-estimate the electron density near the peak. Meanwhile, two-dimensional tomographic reconstruction from GPS/MET data has been demonstrated by many scientists (Rius et al. 1997, 1998; Hajj et al. 2000; Tsai et al. 2002). Tsai et al. (2002) implemented the Multiplicative Algebraic Reconstruction Technique (MART) to reconstruct the ionosphere projected onto the LEO-orbital plane using measured TECs through the receptions of the GPS-to-LEO signals. The reconstructed electron density by the LEO tomography with the compensated TEC yields better results than the original vertical profiles retrieved from the GPS occultation data by the Abel transformation, being in a better agreement in both peak electron density $\mathrm{NmF}_{2}$ and height $\mathrm{hmF}_{2}$ to nearby ionosonde measurements (Tsai et al. 2006, 2009).

The TIP measures horizontal structure of the ionosphere with high precision and high spatial resolution (Chua et al. 2009; Coker et al. 2009; Dymond et al. 2009). The primary source of the nighttime OI $135.6 \mathrm{~nm}$ emission is the radiative recombination process of $\mathrm{O}^{+}$, with a minor contribution from the ion-ion neutralization of $\mathrm{O}^{+}$by $\mathrm{O}^{-}$(Meier 1991). Since the major contribution comes from the direct or radiative recombination, its intensity can be approximated to the square of the electron density (DeMajistre et al. 2004). The OI $135.6 \mathrm{~nm}$ integrated measurements should be thus related to the $\mathrm{NmF}_{2}$ as well as the ionospheric electron content, IEC. Such a relationship can be used to determine a conversion factor that relates the OI $135.6 \mathrm{~nm}$ intensity with $\mathrm{NmF}_{2}$ and IEC, as well as to retrieve these key ionospheric parameters from the observations of this emission. Dymond et al. (2000, 2009) described an algorithm to obtain the electron density profiles by inverting the OI $135.6 \mathrm{~nm}$ nadir measurements. The intensity is calculated using a forward model based on a Chapman distribution for the nighttime atomic oxygen density, defined by the initial input values of $\mathrm{NmF}_{2}$, the F-layer peak altitude $\mathrm{hmF}_{2}$, and the atomic oxygen scale height $\mathrm{H}$. A uniform scale height is assumed below $\mathrm{hmF}_{2}$, while a quadratic function is used to describe the scale height above $\mathrm{hmF}_{2}$. The algorithm iteratively adjusts the initial parameters and the best-fit values that reproduce the observed intensity are used to derive the electron density profile and produce inversions of the TIP radiances.

In this paper, we first find the conversion factor of $\mathrm{NmF}_{2}$ between the TIP radiances and the GOX parameter, and then 
follow Dymond et al. (2009) carrying out the TIP inversions. We further derive and isolate the concurrent data of LEOcompensated tomography by using Tsai et al. (2006), and combine the two results to yield LEO-TIP tomographic inversions (Fig. 1).

\section{OBSERVATION AND RESULT}

The $\mathrm{NmF}_{2}$ and associated $135.6 \mathrm{~nm}$ emission intensity are simulated by using the IRI-01 (Bilitza 2001) and MSISE-90 (Hedin 1991). The models are run to obtain the global values of these parameters at the global fixed local time $2000-2200$ LT in the night of 14 September 2006 at $2100 \mathrm{LT}$, within a latitude-longitude grid of $2.5^{\circ} \times 5^{\circ}$ resolution, inputting the geomagnetic and solar activity conditions from the National Geomagnetic Data Center (NGDC). The scatter plots are made using all the data between $30^{\circ} \mathrm{N}$ and $30^{\circ} \mathrm{S}$. The slope of the straight line fit to the points gives the theoretical conversion factor, which is about 9 (Fig. 2). Meanwhile, concurrent and co-located measurements of the TIP radiances and $\mathrm{GOX} \mathrm{NmF}_{2}$ (Abel inversion) at the global fixed 2000 - 2200 LT in the night of 14 September 2006 are used to determine the observed conversion factor, which is also 9 (Fig, 2). This conversion factor is used to retrieve $\mathrm{NmF}_{2}$ from the TIP intensity. Note that this factor will depend on local time, season, and solar activity. In the examples here, the conversion factor corresponding to the particular observing conditions has been used.

We focus on observations carried out along track 1 (FN 001; DID 06) and track 2 (FN 003; DID 02) at about $540 \mathrm{~km}$ altitude in the night of 14 September 2006 (Fig. 3). Inversion of the TIP radiances is mainly based on Dymond et al. (2000, 2009). A Chapman profile is assumed for the electron density distribution, which depends on the $\mathrm{NmF}_{2}, \mathrm{hmF}_{2}$, and scale height $\mathrm{H}$. The inversion is carried out at every $1^{\circ}$ latitude. A forward model based on the Chapman approximation is used to calculate the observed intensities, where initial values for $\mathrm{NmF}_{2}, \mathrm{hmF}_{2}$, and scale parameters are to be assumed. The initial $\mathrm{NmF}_{2}$ value is obtained from the TIP radiance using the observed conversion factor, while the initial $\mathrm{hmF}_{2}$ is assumed to be $300 \mathrm{~km}$ altitude and scale height to be $60 \mathrm{~km}$. An iterative approach is used to get best fit of the input parameters $\left(\mathrm{NmF}_{2}, \mathrm{hmF}_{2}\right.$, and scale height), which are determined when the forward model reproduces the observed intensity for a $\chi^{2}$ variation less than $0.1 \%$ between successive iterations. The inverted electron density profiles for the two cases used here are displayed in Figs. 4a and $5 \mathrm{a}$. It can be seen that the equatorial ionization anomaly (EIA) in electron density along the satellite flight plane can be clearly observed, however the $\mathrm{hmF}_{2}$ along the track is unchanged at about $330 \mathrm{~km}$ altitude.

As the assumption of spherical symmetry used in the Abel integral transform is not realistic in general, we adopt the improved approach of Tsai et al. $(2006,2009)$ consider- ing and deriving horizontal gradients of the electron density by close-up occultation profiles retrieved from the standard Abel inversion. That is the density distribution is used to compensate the TEC from Abel inversion using the difference between the tangent point electron density and the real electron densities along the occultation rays. Figures $4 \mathrm{~b}$ and $5 \mathrm{~b}$ illustrate the compensated LEO tomography results of the two flight plans obtained from the GOX data. Although the EIA structure is much weakened, the $\mathrm{hmF}_{2}$ variation can be clearly found.

Since the TIP provides a distinct electron density structure and the LEO tomography yields a more realistic $\mathrm{hmF}_{2}$ variation, we then combine the two observations by forwarding the $\mathrm{LEO} \mathrm{hmF}_{2}$ to the TIP retrieval (Figs. 4c, 5c). By this process we can reconstruct ionospheric electron density with well distinguished EIA peaks, while retaining the altitude information. The LEO-TIP profiles show that the high sensitivity as well as the spatial and temporal resolution of the TIP is helpful for detailed information of the horizontal electron density structures than the other technique.

Figures 6 and 7 illustrate the electron density profiles obtained from LEO-TIP tomography together with those from LEO tomography and the original GOX Abel retrieval. For both the tracks, the TIP intensity at $-30^{\circ} \mathrm{N}$ is extremely low and this has caused the electron density of the corresponding profiles to be much less than those from LEO tomography and GOX. The $\mathrm{NmF}_{2}$ from LEO-TIP tomography and from solo LEO tomography more or less agree between $0-30^{\circ} \mathrm{N}$, while they are far off at other latitudes. The latitudinal distributions of $\mathrm{NmF}_{2}$ from the TIP inversion (or LEO-TIP tomography), LEO tomography, and GOX retrieval show that the TIP is more efficient in reproducing spatial variations (Fig. 8). On the other hand, the latitudinal distributions of $\mathrm{hmF}_{2}$ from the TIP inversion are about constant, GOX retrieval is scattered, and LEO (or LEO-TIP) tomography yields more realistic values (Fig. 9).

\section{DISCUSSION AND CONCLUSION}

The OI $135.6 \mathrm{~nm}$ emission for Fig. 2 has been simulated taking into account the contributions from both the radiative recombination as well as the ion-ion neutralization (Tinsley and Bittencourt 1975; Melendez-Alvira et al. 1999). The perfect straight line fit to the simulated data underlines the fact that the ion-ion neutralization is not significant compared to the dominant radiative recombination process. The inversion algorithm used here, hence, considers only the direct (radiative) recombination while computing the emission. Figure 2 also suggests that a simple conversion factor can be used to determine $\mathrm{NmF}_{2}$ from the OI $135.6 \mathrm{~nm}$ nadir integrated intensity measurements. The agreement between the theoretical and the observed conversion factor shows that the simulations are reliable in spite of the limitations of the models used. The details of the conversion factor will be 
discussed in a forthcoming communication. One of the immediate applications of the conversion factor is in determining the $\mathrm{NmF}_{2}$ values that serve as more realistic input to the inversion algorithm.

There is an overall intensity variation from track 1 to track 2 (Fig. 3). The anomaly peaks in Fig. 4a are more pronounced than that in Fig. 5a. The two satellite scans selected here have almost the same latitudinal coverage, and are separated by about $35^{\circ}$ in longitude. The observed intensity difference of the two orbits could come from this difference in the longitudes. A similar, but less pronounced, difference in the electron densities can be seen in the LEO tomography data also (Figs. $4 \mathrm{~b}$ and 5b).

The inversion procedure has reproduced the spatial structures in the observed airglow intensity (Fig. 8) quite well. It can be seen that, compared to the LEO tomography profiles, the TIP inversion gives a better result in that the anomaly peaks are well separated. This shows that the TIP is more sensitive to horizontal gradients and is very useful in re-constructing fine structures in the spatial distribution of electron density. But, the $135.6 \mathrm{~nm}$ airglow intensity from the TIP is proportional to the vertical column integral of the square of the electron density and, therefore, contains no
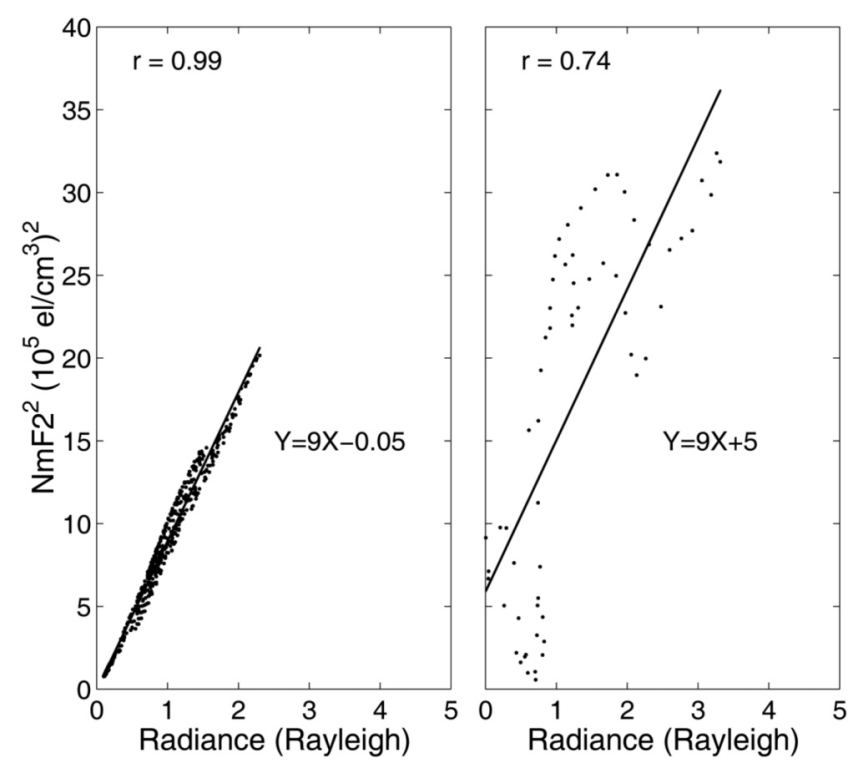

Fig. 2. The conversion factor between $\mathrm{NmF}_{2}$ and $135.6 \mathrm{~nm}$ radiance derived from the IRI and MSISE models (left), and that obtained using GOX $\mathrm{NmF}_{2}$ (Abel inversion) and TIP radiance (right). The $\mathrm{NmF}_{2}$ and $135.6 \mathrm{~nm}$ radiance are in $10^{5} \mathrm{el} \mathrm{cm}^{-3}$ and Rayleigh, respectively. The correlation coefficients for the simulation and observation are 0.99 and 0.74 , respectively.

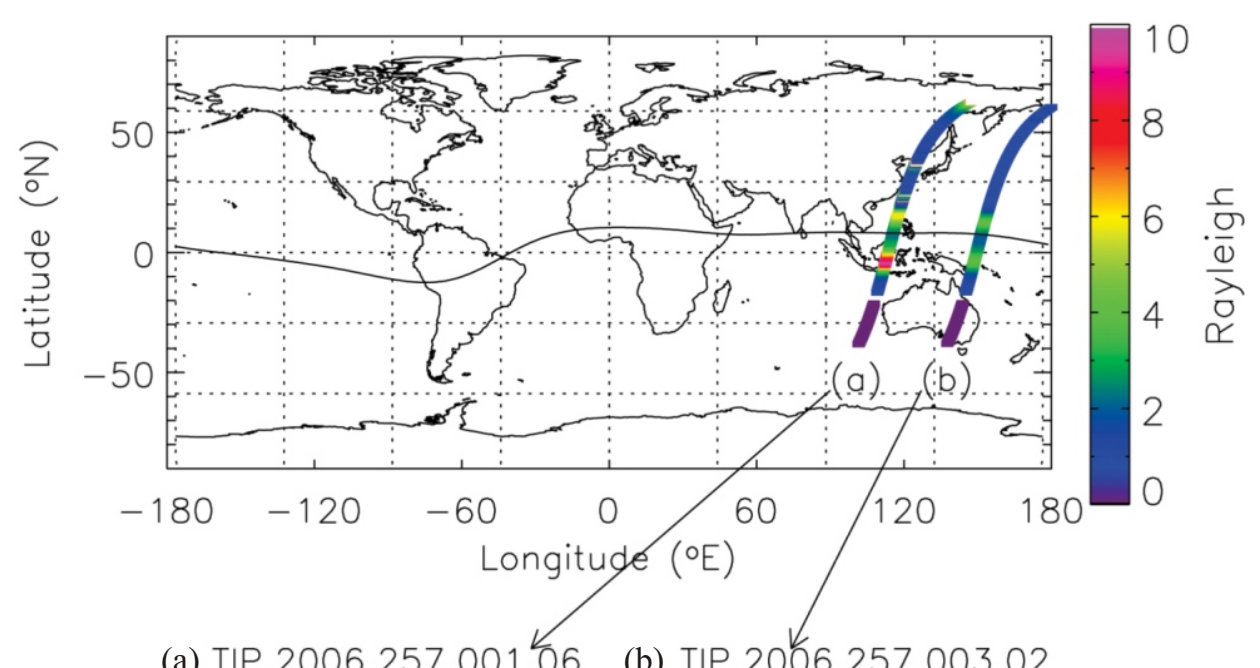

$\begin{array}{ll}\text { (a) TIP.2006.257.001.06 } & \text { (b) TIP.2006.257.003.02 }\end{array}$
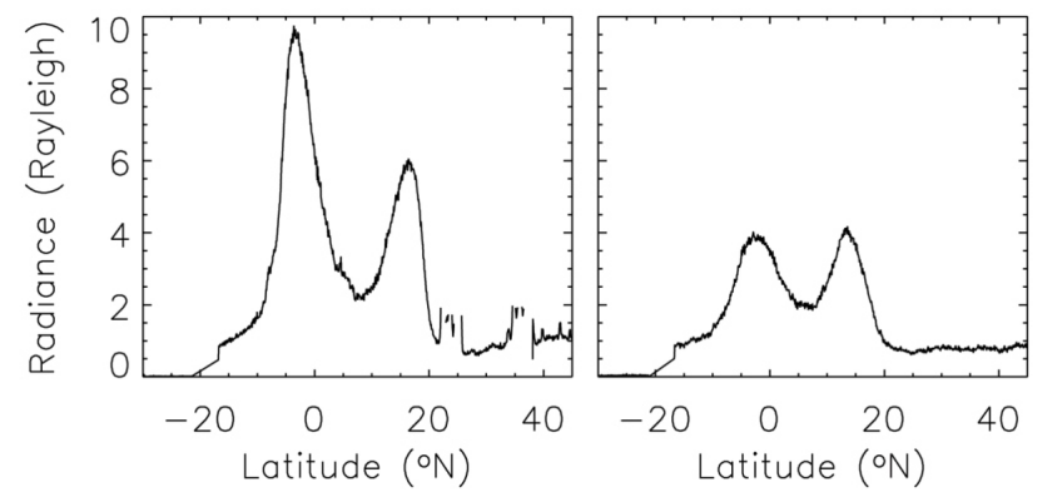

Fig. 3. The TIP observations along: (a) Track 1 (FN 001; DID 06), and (b) Track 2 (FN 003; DID 02) at about 540 km altitude in the night of 14 September 2006. The color code (top) and the solid lines (bottom) indicate the TIP intensity along the track. 


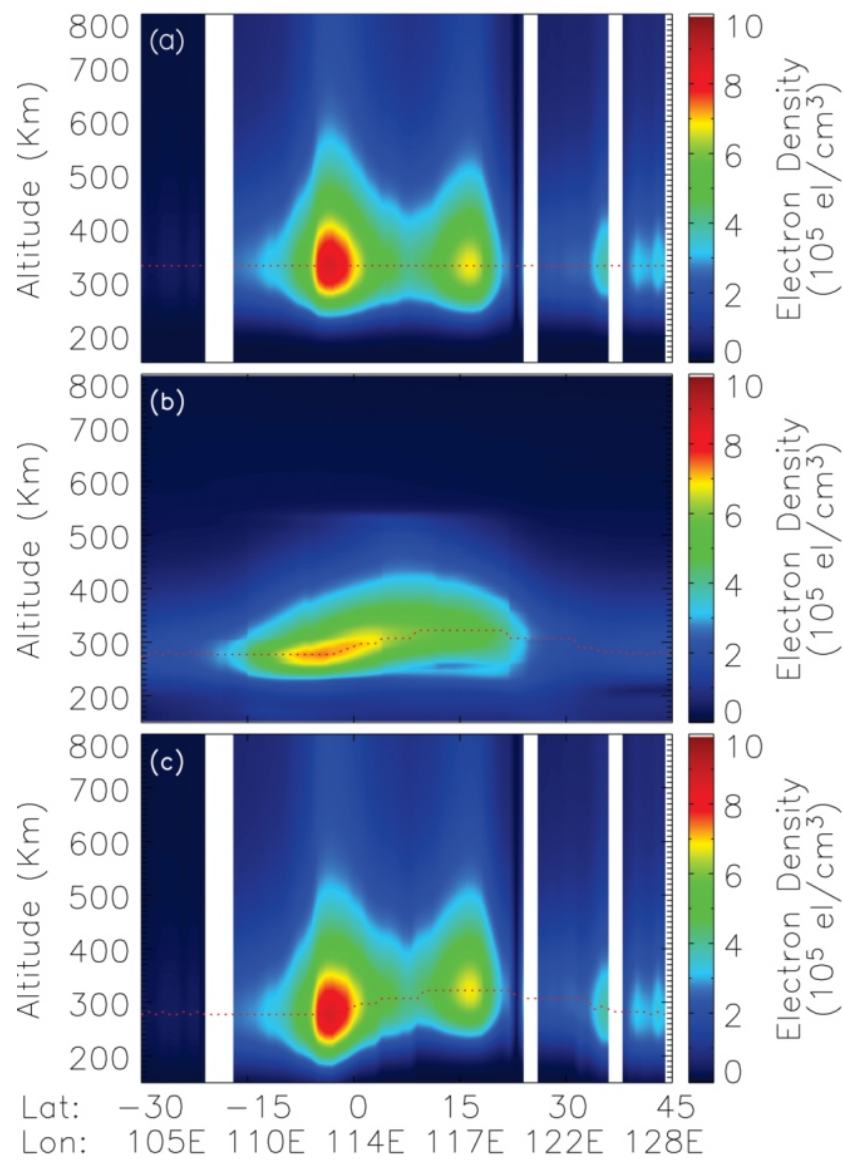

Fig. 4. Ionospheric tomography of Track 1 from (a) TIP, (b) LEO, and (c) LEO-TIP inversions. The white space denotes data gap or noise. The dotted lines denote the $\mathrm{hmF}_{2}$.

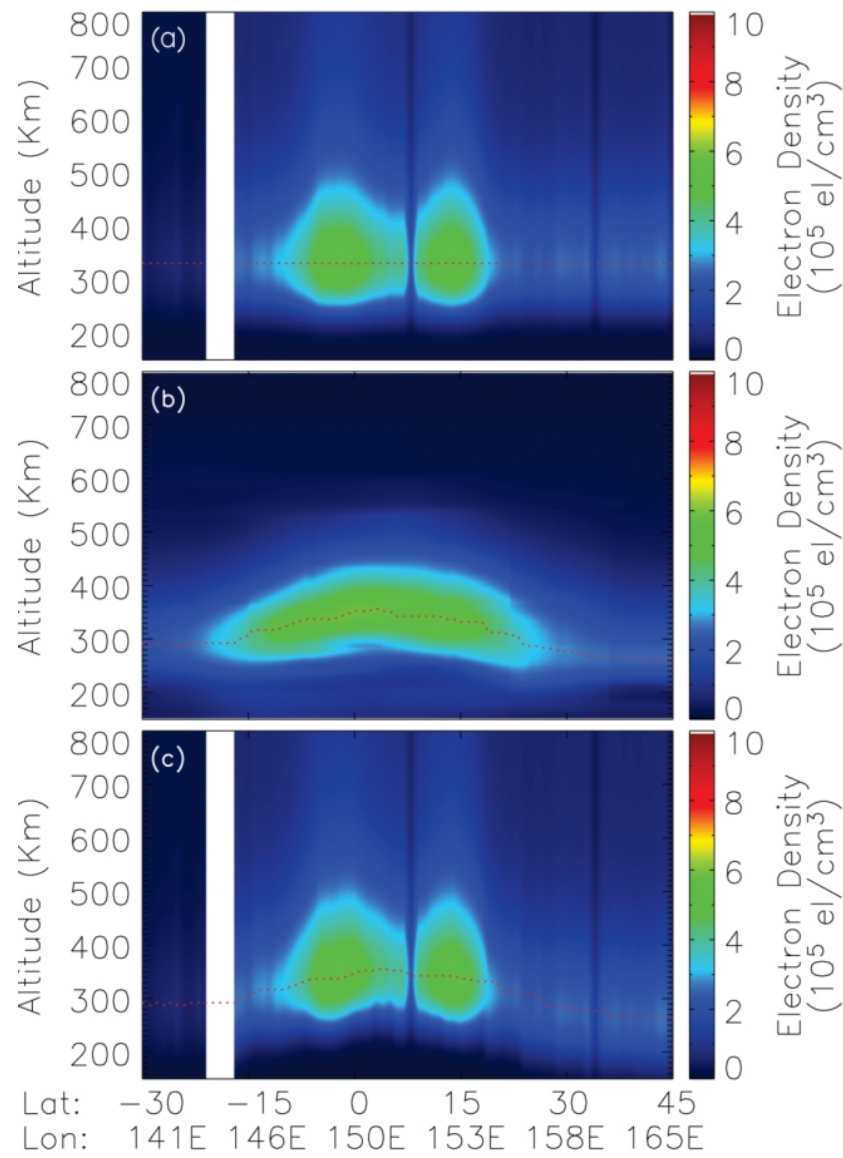

Fig. 5. Ionospheric tomography of Track 2 from (a) TIP, (b) LEO, and (c) LEO-TIP inversions. The white space denotes data gap or noise. The dotted lines denote the $\mathrm{hmF}_{2}$.

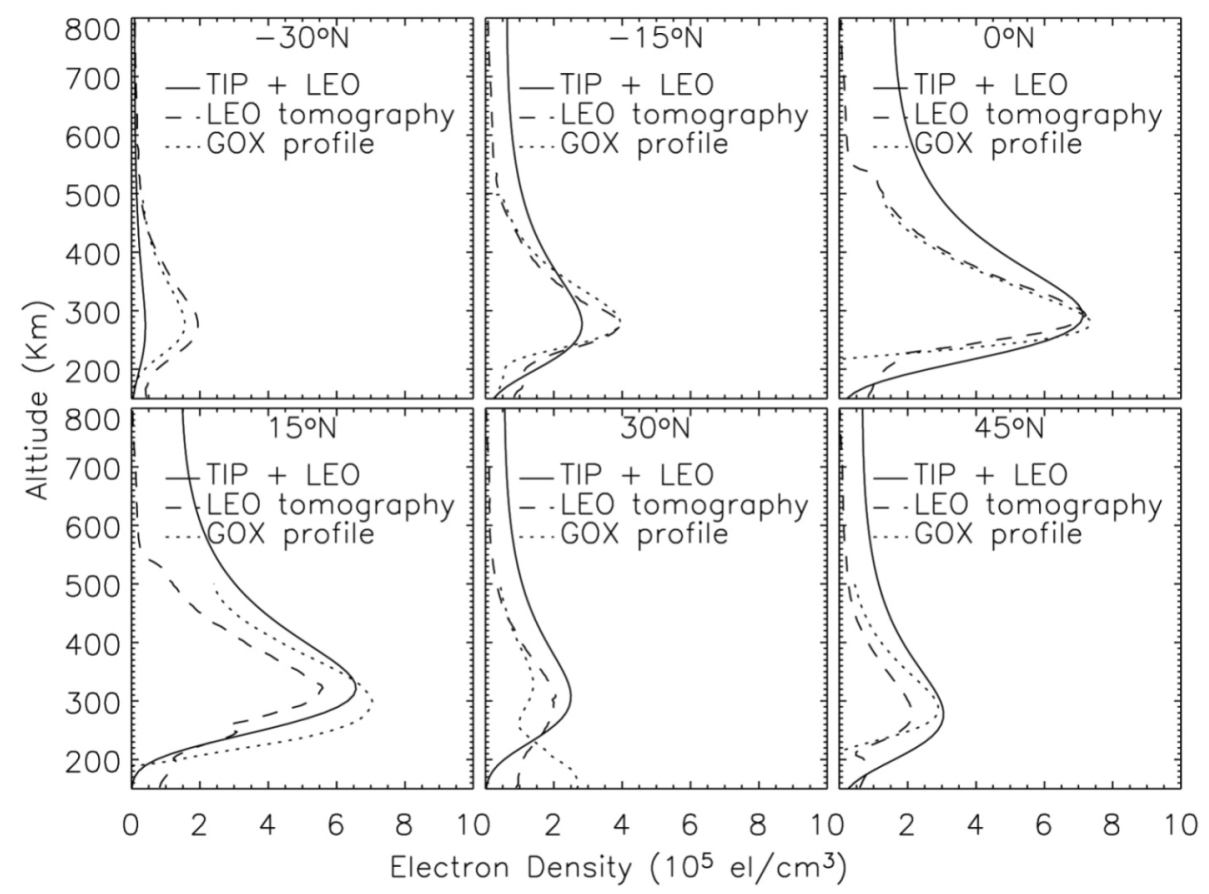

Fig. 6. The electron density profiles for track 1. The solid, dashed and dotted lines denote the profiles from LEO-TIP hmF 2 , LEO, and GOX (Abel inversion), respectively. The profiles are shown at every $5^{\circ}$ latitude between -30 and $45^{\circ} \mathrm{N}$. 


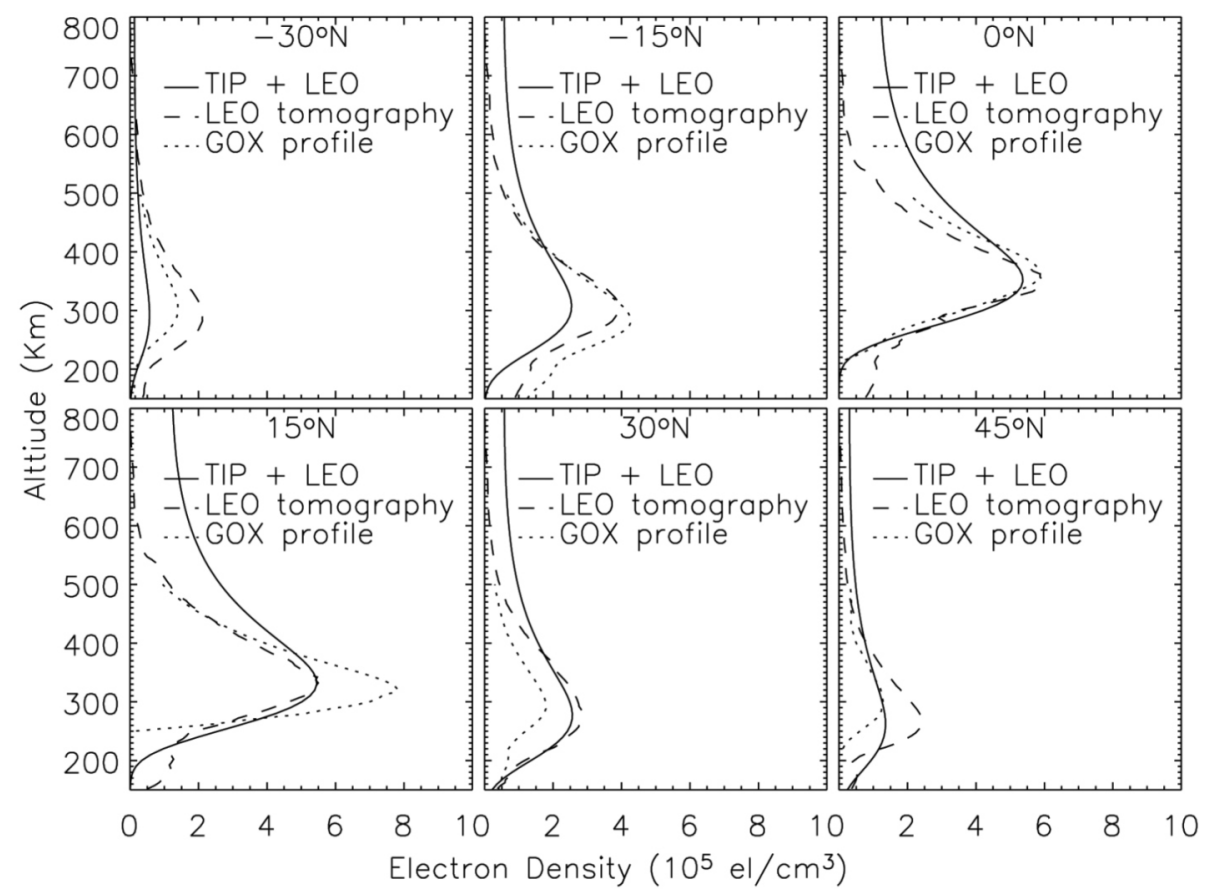

Fig. 7. The electron density profiles for track 2 . The solid, dashed, and dotted lines denote the profiles from LEO-TIP hmF 2 , LEO, and GOX (Abel inversion), respectively. The profiles are shown at every $5^{\circ}$ latitude between -30 and $45^{\circ} \mathrm{N}$.
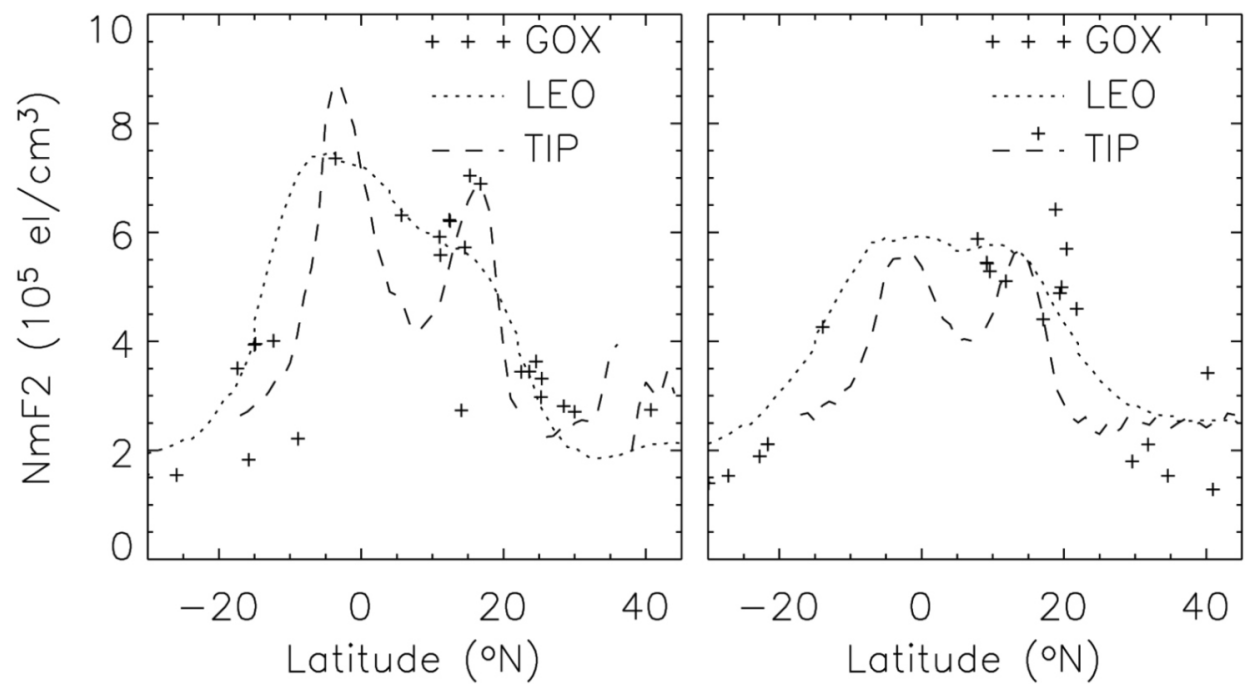

Fig. 8 Ionospheric $\mathrm{NmF}_{2}$ for track 1 (left) and track 2 (right). The dashed line, dotted line, and cross symbol denotes the NmF 2 of the TIP (LEO-TIP), LEO, and GOX (Abel inversion), respectively.

altitude information. The altitude variation of the electron density has been poorly reproduced in the inversion (Fig. 9).

The GPS total electron data are in the form of an occultation or "limb scan" and therefore these data provide high quality altitude information. However, the GPS data are integrated electron densities along the line-of-sight to the GPS satellite and therefore may be affected by gradients along the line-of-sight. Consequently, the LEO tomography gives only an overall electron density variation (Fig. 8), and even the anomaly peaks are not well distinguishable, while this method can reproduce the altitude variation (Fig. 9). Thus, this work shows that by combining the two procedures, it is possible to take the advantages of both methods to reconstruct two dimensional electron densities (Figs. 4c, 5c).

We present the results of inversions of the TIP radiances in conjunction with the LEO tomography. The preliminary results presented here demonstrate that the TIP serves the very objective of providing information about the horizontal 

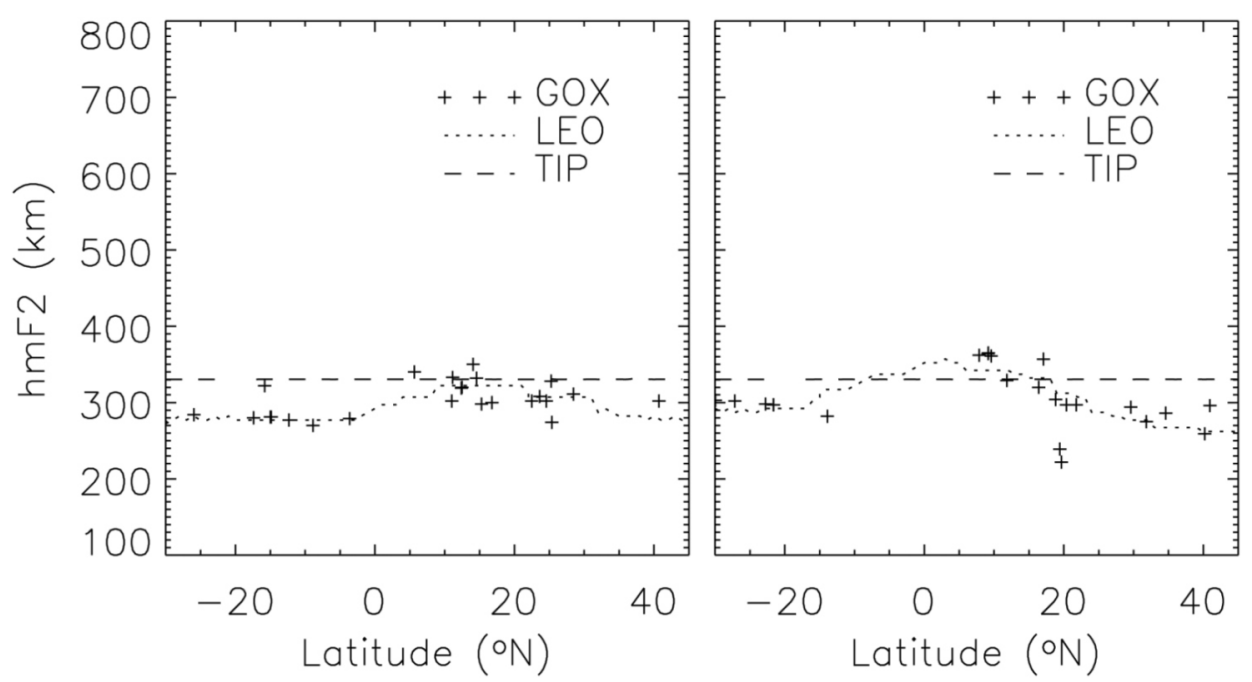

Fig. 9. Ionospheric $\mathrm{hmF}_{2}$ for track 1 (left) and track 2 (right). The dashed line, dotted line, and cross symbol denotes the hmF $\mathrm{F}_{2}$ of the TIP, LEO (LEO-TIP), and GOX (Abel inversion), respectively.

gradients in electron density, which is a necessary input for LEO tomography. In this paper, we show TIP OI $135.6 \mathrm{~nm}$ integrated measurements can be converted to the ionospheric electron content, IEC (Fig. 1). On the other hand, Tsai et al. (2002) successfully develop tomographic imaging of the ionosphere using the GPS/MET and NNSS data. It should be applicable to combine the GOX compensated TEC and the TIP IEC, replacing the NNSS data, to carry out a better LEO-TIP tomographic inversion (Fig. 1).

Acknowledgments The authors wish to thank Po-Ya Chang in Institute of Space, National Central University for processing the FORMOSAT-3/COSMIC GOX data. The work has been supported by Project 96-NSPO(B)-SPFA07-03(A).

\section{REFERENCES}

Bilitza, D., 2001: International Reference Ionosphere 2000. Radio Sci., 36, 261-275, doi: 10.1029/2000RS002432. [Link]

Cheng, C. Z., Y. H. Kuo, R. A. Anthes, and L. Wu, 2006: Satellite constellation monitors global and space weather. EOS, 87, 166 pp, doi: 10.1029/2006EO170003. [Link]

Chua, D. H., K. F. Dymond, S. A. Budzien, C. Coker, and J. Y. Liu, 2009: Horizontal ionospheric electron density gradients observed by FORMOSAT-3/COSMIC TIP: Spatial distributions and effects on VLF wave propagation at mid-latitudes. Terr. Atmos. Ocean. Sci., 20, 251-259, doi: 10.3319/TAO.2008.01.16.01(F3C). [Link]

Coker, C., K. F. Dymond, S. A. Budzien, D. H. Chua, J. Y. Liu, D. N. Anderson, S. Basu, and T. R. Pedersen, 2009: Observations of the ionosphere using the Tiny Ionospheric Photometer. Terr. Atmos. Ocean. Sci., 20, 227-235, doi: 10.3319/ TAO.2008.01.18.02(F3C). [Link]

DeMajistre, R., L. J. Paxton, D. Morrison, J. H. Yee, L. P.
Goncharenko, and A. B. Christensen, 2004: Retrievals of nighttime electron density from Thermosphere Ionosphere Mesosphere Energetics and Dynamics (TIMED) mission Global Ultraviolet Imager (GUVI) measurements. J. Geophys. Res., 109, A05305, doi: 10.1029/2003JA010296. [Link]

Dymond, K. F., J. B. Nee, and R. J. Thomas, 2000: The tiny ionospheric photometer: An instrument for measuring ionospheric gradients for the COSMIC constellation. Terr. Atmos. Ocean. Sci., 11, 273-290.

Dymond, K. F., S. A. Budzien, D. H. Chua, C. Coker, and J. Y. Liu, 2009: Tomographic reconstruction of the low-latitude nighttime electron density using FORMOSAT-3/COMSIC radio occultation and UV photometer data. Terr. Atmos. Ocean. Sci., 20, 215-226, doi: 10.3319/TAO.2008.01.15. 01(F3C). [Link]

Fjeldbo, G. and V. R. Eshleman, 1968: The atmosphere of Mars analyzed by integral inversion of the Mariner IV occultation data. Planet Space Sci., 16, 1035-1059, doi: 10.1016/0032-0633(68)90020-2. [Link]

Fjeldbo, G., A. J. Kliore, and V. R. Eshleman, 1971: The neutral atmosphere of Venus as studied with the mariner $\mathrm{V}$ radio occultation experiments. Astron. J., 76, 123-140, doi: 10.1086/111096. [Link]

Hajj, G. A. and L. J. Romans, 1998: Ionospheric electron density profiles obtained with the Global Positioning System: Results from the GPS/MET experiment. Radio Sci., 33, 175-190, doi: 10.1029/97RS03183. [Link]

Hajj, G. A., L. C. Lee, X. Pi, L. J. Romans, W. S. Schreiner, P. R. Straus, and C. Wang, 2000: COSMIC GPS ionospheric sensing and space weather. Terr. Atmos. Ocean. Sci., 11, 235-272.

Hedin, A. E., 1991: Extension of the MSIS Thermospheric Model into the Middle and Lower Atmosphere. J. Geophys. Res., 96, 1159-1172, doi: 10.1029/90JA02125. [Link] 
Lei, J., S. Syndergaard, A. G. Burns, S. C. Solomon, W. Wang, Z. Zeng, R. G. Roble, Q. Wu, Y. H. Kuo, J. M. Holt, S. R. Zhang, D. L. Hysell, F. S. Rodrigues, and C. H. Lin, 2007: Comparison of COSMIC ionospheric measurements with ground-based observations and model predictions: Preliminary results. J. Geophys. Res., 112, A07308, doi: 10.1029/2006JA012240. [Link]

Lin, C. H., J. Y. Liu, T. W. Fang, P. Y. Chang, H. F. Tsai, C. H. Chen, and C. C. Hsiao, 2007: Motions of the equatorial ionization anomaly crests imaged by FORMOSAT-3/COSMIC. Geophys. Res. Lett., 34, L19101, doi: 10.1029/2007 GL030741. [Link]

Lin, C. H., J. Y. Liu, C. C. Hsiao, C. H. Liu, C. Z. Cheng, P. Y. Chang, H. F. Tsai, T. W. Fang, C. H. Chen, and M. L. Hsu, 2009: Global ionospheric structure imaged by FORMOSAT-3/COSMIC: Early results. Terr. Atmos. Ocean. Sci., 20, 171-179, doi: 10.3319/TAO.2008.01.18.01(F3C). [Link]

Meier, R. R., 1991: Ultraviolet spectroscopy and remote sensing of the upper atmosphere. Space Sci. Rev., 58, 1-185, doi: 10.1007/BF01206000. [Link]

Melendez-Alvira, D. J., R. R. Meier, J. M. Picone, P. D. Feldman, and B. M. McLaughlin, 1999: Analysis of oxygen nightglow measured by the Hopkins ultraviolet telescope: Implications for ionospheric partial radiative recombination rate coefficients. J. Geophys. Res., 104, 14901-14913, doi: 10.1029/1999JA900136. [Link]

Rius, A., G. Runi, and L. Cucurull, 1997: Improving the vertical resolution of ionospheric tomography with GPS occultations. Geophys. Res. Lett., 24, 2291-2294, doi: 10.1029/ 97GL52283. [Link]

Rius, A., G. Ruffini, and A. Romeo, 1998: Analysis of Ionospheric Electron Density distribution from GPS/MET occulations. IEEE Trans. Geosci. Remote Sensing, 36, 383394, doi: 10.1109/36.662724. [Link]

Rocken, C., Y. H. Kuo, W. Schreiner, D. Hunt, S. Sokolovskiy, and C. McCormick, 2000: COSMIC system description. Terr. Atmos. Ocean. Sci., 11, 21-52.
Schreiner, W. S., S. V. Sokolovskiy, C. Rocken, and D. C. Hunt, 1999: Analysis and validation of GPS/MET radio occultation data in the ionosphere. Radio Sci., 34, 949-966, doi: 10.1029/1999RS900034. [Link]

Schreiner, W., C. Rocken, S. Sokolovskiy, S. Syndergaard, and D. Hunt, 2007: Estimates of the precision of GPS radio occultations from the COSMIC/FORMOSAT-3 mission. Geophys. Res. Lett., 34, L04808, doi: 10.1029/2006GL 027557. [Link]

Tinsley, B. A. and J. A. Bittencourt, 1975: Determination of F region height and peak electron density at night using airglow emissions from atomic oxygen. J. Geophys. Res., 80, 2333-2337, doi: 10.1029/JA080i016p02333. [Link]

Tsai, L. C. and W. H. Tsai, 2004: Improvement of GPS/MET ionospheric profiling and validation using the Chung-Li ionosonde measurements and the IRI model. Terr. Atmos. Ocean. Sci., 15, 589-607.

Tsai, L. C., W. H. Tsai, W. S. Schreiner, F. T. Berkey, and J. Y. Liu, 2001: Comparisons of GPS/MET retrieved ionospheric electron density and ground based ionosonde data. Earth Planets Space, 53, 193-205.

Tsai, L. C., C. H. Liu, W. H. Tsai, and C. T. Liu, 2002: Tomographic imaging of the ionosphere using the GPS/MET and NNSS data. J. Atmos. Sol.-Terr. Phys., 64, 2003-2011, doi: 10.1016/S1364-6826(02)00218-3. [Link]

Tsai, L. C., W. H. Tsai, J. Y. Chou, and C. H. Liu, 2006: Ionospheric tomography from a reference GPS/MET experiment through the IRI model. Terr. Atmos. Ocean. Sci., 17, 263-276.

Tsai, L. C., C. H. Liu, and T. Y. Hsiao, 2009: Profiling of ionospheric electron density based on FormoSat-3/COSMIC data: Results from the intense observation period experiment. Terr. Atmos. Ocean. Sci., 20, 181-191, doi: 10.3319/ TAO.2007.12.19.01(F3C). [Link]

Yunck, T. P., 2002: An overview of atmospheric radio occultation. J. Global Positioning Systems, 1, 58-60. 